Proceedings

\title{
Record of Amitermes (Blattodea, Termitidae) Species in Togo West Africa $^{+}$
}

\author{
Toblie Quashie Effowe ${ }^{1}$, Boris Dodji Kasseney ${ }^{1 *}$, Abdoulaye Baïla Ndiaye ${ }^{2}$, Bassan Banibea Sanbena ${ }^{1}$, \\ Adolé Isabelle Glitho ${ }^{1}$
}

Citation: Effowe, T.Q.; Kasseney, B.D.; Ndiaye, A.B.; Sanbena, B.B.; Glitho, A.I. Record of Amitermes (Blattodea, Termitidae) Species in Togo West Africa, in Proceedings of the 1st International Electronic Conference on Entomology, 1-15 July 2021, MDPI: Basel, Switzerland, doi:10.3390/IECE-10497

Published: 1 July 2021

Publisher's Note: MDPI stays neutral with regard to jurisdictional claims in published maps and institutional affiliations.

Copyright: (c) 2021 by the authors. Submitted for possible open access publication under the terms and conditions of the Creative Commons Attribution (CC BY) license (http://creativecommons.org/licenses /by/4.0/).
1 Laboratoire d'Entomologie Appliquée, Département de Zoologie, Université de Lomé, 01 BP 1515, Lomé 01, Togo.; q.effowe@gmail.com; borisdodji@gmail.com, sanbenab@gmail.com, iglitho@yahoo.fr

2 Laboratoire de Zoologie des Invertébrés terrestres, Département de Biologie Animale, Institut Fondamental d'Afrique Noire, Université Cheikh Anta Diop de Dakar, BP : 206, Dakar, Sénégal; abdoulaye.ndiaye@ucad.edu.sn

* borisdodji@gmail.com, Phone: 0022890615674

† Presented at the 1st International Electronic Conference on Entomology (IECE 2021), 1-15 July 2021; Available online: https://iece.sciforum.net/.

\begin{abstract}
This study combined morphological traits with morphometric measurements to identify Amitermes species collected inside transects laid in three parks: Fosse aux Lions, Galangashie and Fazao Malfakassa. Samples were grouped by morphospecies and measurements of body parts (length/width of head, mandible, pronotum, gula and hind tibia) were taken. Four Amitermes species were identified: Amitermes evuncifer, A. guineensis, A. spinifer and A. truncatidens. Among the four species, A. guineensis had the longest head $(1.225 \pm 0.031 \mathrm{~mm})$ while Amitermes spinifer had the shortest $(0.933 \pm 0.018 \mathrm{~mm})$ one.
\end{abstract}

Keywords: Termites systematic; morphometric measurements; Amitermes species

\section{Introduction}

In most of the African countries, termites systematic is hampered by the confusion in the identification of many species [1-4]. One of the most common way to identify termites is the comparison of samples with reference species which most of the time are not correctly identified. Several reference works done by famous taxonomists [5-11] are also used in the identification of termite. Although these reference works were published several decades ago, they are actually useful and are still widely used by many researchers for termite's identification.

Most of the reference works combine morphological traits (shape, color of different part of the body) and morphometric measurements (length, width and depth of certain part of the body of termites). For Amitermes species of African and Arabian countries, these features were deeply described and illustrated by Sands [11]. In this study, both morphological features and morphometric measurements were used to sort out Amitermes species collected in central and northern part of Togo.

\section{Material and methods}

\subsection{Study sites}

Termites were collected from three different parks (Figure 1) including: Fosse aux lions $\left(10^{\circ} 46^{\prime}-10^{\circ} 49^{\prime} \mathrm{N}\right.$ and $\left.0^{\circ} 11^{\prime}-0^{\circ} 14^{\prime} \mathrm{E}\right)$, Galangashie $\left(10^{\circ} 19^{\prime}-20^{\circ} 28^{\prime} \mathrm{N}\right.$ and $0^{\circ} 14^{\prime}-$ $\left.0^{\circ} 27^{\prime} \mathrm{E}\right)$ both located in the northern part of Togo, and Fazao-Malfakassa $\left(8^{\circ} 20^{\prime}-9^{\circ} 35^{\prime} \mathrm{N}\right.$ and $0^{\circ} 35^{\prime}-1^{\circ} 02^{\prime} \mathrm{E}$ ) located in the centre of the country. 


\section{Legend}

¿ Sampling sites

- Cities
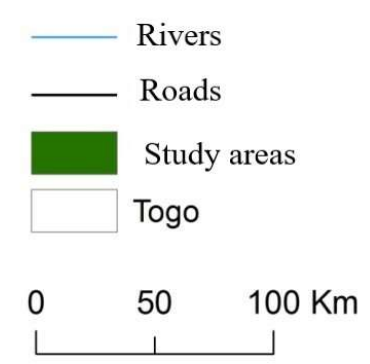

Projection: WGS 1984 Source: IGN,Donné-es de Terrain Realisation: LBEV/Folega $F$ Edition: Janvier 2016, Lomé-Togo

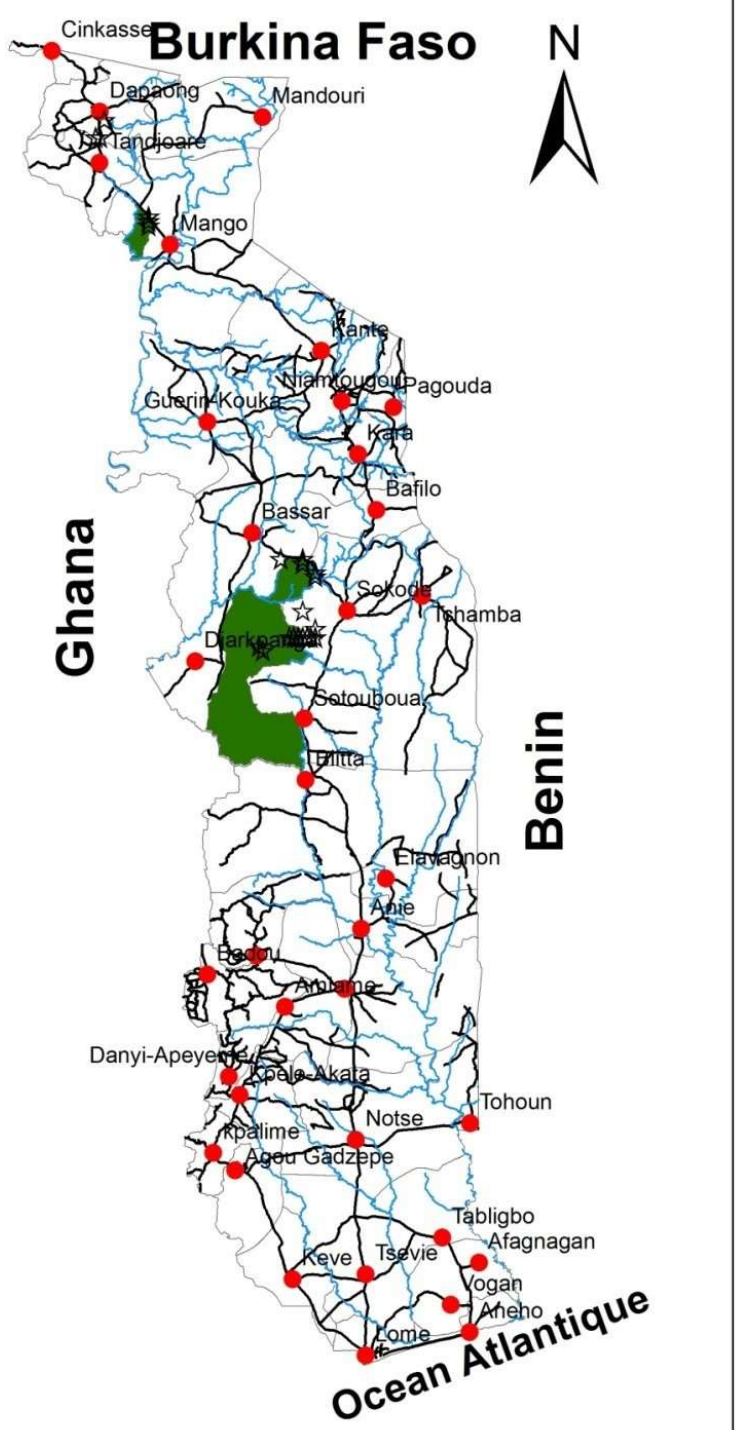

Figure 1: Map of Togo with prospected parks

The first two parks (Fosse aux lions and Galangashi) are characterized by a sudanian tropical climate with a long dry season (November to May) and a long raining season (June to October). In these two parks, the mean temperatures range from $29 \pm 2^{\circ} \mathrm{C}$ during the raining season and $30 \pm 3^{\circ} \mathrm{C}$ during dry season. The annual rainfall is $986 \mathrm{~mm}$ and the landscape is a shrubby savanna. Fazao-Malfakassa is characterized by a semi-humid tropical climate with a long rainy season (from April to October) and a long dry season (from November to March). The mean temperatures range from $27,5 \pm 1,5^{\circ} \mathrm{C}$ during dry season and $27 \pm 2^{\circ} \mathrm{C}$ during rainy season. The annual rainfall is $120 \mathrm{~mm}$ and the landscapes is composed of dry forests, gallery forests, shrubby savanna and fallows.

\subsection{Termites sampling}

Belt transects were used to sample termites in each of the identified landscape found in the three study areas. The standard protocol [12] adapted to the savanna ecosystem [1314] was used in our study. A total of 81 transects were laid in three mentioned parks and surrounding fallows. Each transect of $100 \times 5 \mathrm{~m}$ was divided into 20 sampling units of $5 \times 2$ $\mathrm{m}$ which were sampled for 15 minutes [15-16]. Termite were searched within the frame of each sampling unit inside mounds, litter, wood, and grasses on trees by a well-trained collector. After this searching on the surface, termites were also searched throughout eight soil 
scrapes of $15 \times 15 \times 10 \mathrm{~m}$ [15-16]. Sampled termites were kept in $95 \%$ ethanol inside labeled vials and brought to the laboratory for identification.

\subsection{Termites identification}

Morphological traits of soldier including number of antennal segments, shape of mandibles and the position of the mandible tooth were used to sort out Amitermes species according to Sands [11]. Measurements were made with a stereomicroscope (Leica EZ4) equipped with an integrated camera. Voucher specimen are conserved in the "Laboratoire d'Entomologie" of the University of Lomé (Togo).

Factorial discriminant analysis (using morphometric data) was used to separate species with close measurements.

\section{Results}

Four species of Amitermes including Amitermes evuncifer Silvestri,1912 (Table 1, Figure 2), Amitermes guineensis Sands, 1992 (Table 2, Figure 3), Amitermes spinifer Silvestri, 1914 (Table 3, Figure 4) and Amitermes truncatidens Sands, 1959 (Table 4, Figure 5) were unambiguously identified. The soldier of all the other four species have 14 antennal segments except Amitermes spinifer which have 13. The ranges and measurements of head length, head width, left mandible length, pronotum width, gula width and hind tibia length for each species are presented in below Tables (Table $1-4)$..

\subsection{Amitermes evuncifer}

Table 1. The measurements (mm) of the soldiers of Amitermes evuncifer.

\begin{tabular}{ccc}
\hline & Range $(\mathbf{m m})$ & Mean \pm SD \\
\hline Head length & $1.06-1.19$ & $1.134 \pm 0.049$ \\
Head width & $0.93-0.975$ & $0.954 \pm 0.014$ \\
Left mandible length & $0.594-0.709$ & $0.660 \pm 0.038$ \\
Pronotum width & $0.587-0.615$ & $0.600 \pm 0.011$ \\
Gula width & $0.252-0.3$ & $0.279 \pm 0.016$ \\
Hind tibia length & $0.828-1.2$ & $0.970 \pm 0.126$ \\
\hline
\end{tabular}

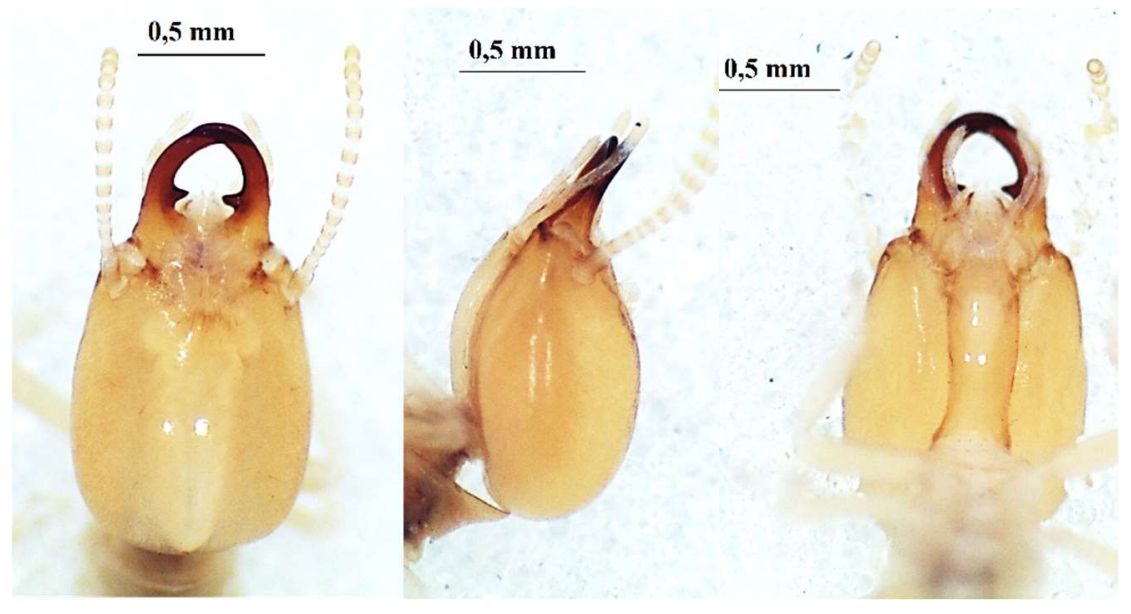

Figure 2. The head of Amitermes evuncifer soldier in dorsal view (left), lateral view (middle) and ventral view (right). 


\subsection{Amitermes guineensis}

Table 2. The measurements (mm) of the soldiers of Amitermes guineensis.

\begin{tabular}{ccc}
\hline & Range $(\mathbf{m m})$ & Mean \pm SD \\
\hline Head length & $1.17-1.27$ & $1.225 \pm 0.031$ \\
Head width & $0.677-0.979$ & $0.871 \pm 0.008$ \\
Left mandible length & $0.611-0.795$ & $0.722 \pm 0.058$ \\
Pronotum width & $0.139-0.287$ & $0.438 \pm 0.013$ \\
Gula width & $0.139-0.287$ & $0.213 \pm 0.041$ \\
Hind tibia length & $0.503-0.519$ & $0.509 \pm 0.005$ \\
\hline
\end{tabular}

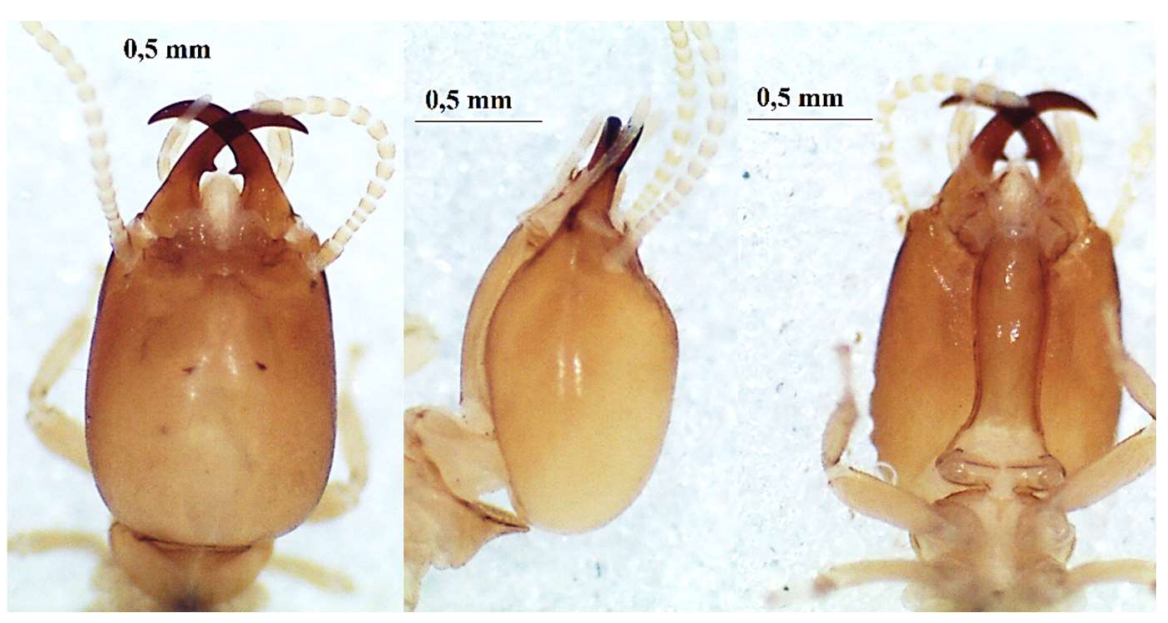

Figure 3. The head of Amitermes guineensis soldier in dorsal view (left), lateral view (middle) and ventral view (right)..

\subsection{Amitermes spinifer}

Table 3. The measurements (mm) of the soldiers of Amitermes spinifer.

\begin{tabular}{ccc}
\hline & Range $(\mathbf{m m})$ & Mean \pm SD \\
\hline Head length & $0.865-0.954$ & $0.933 \pm 0.018$ \\
Head width & $0.681-0.742$ & $0.726 \pm 0.027$ \\
Left mandible length & $0.585-0.624$ & $0.613 \pm 0.017$ \\
Pronotum width & $0.472-0.492$ & $0.486 \pm 0.009$ \\
Gula width & $0.257-0.26$ & $0.288 \pm 0.020$ \\
Hind tibia length & $0.642-0.65$ & $0.643 \pm 0.017$ \\
\hline
\end{tabular}




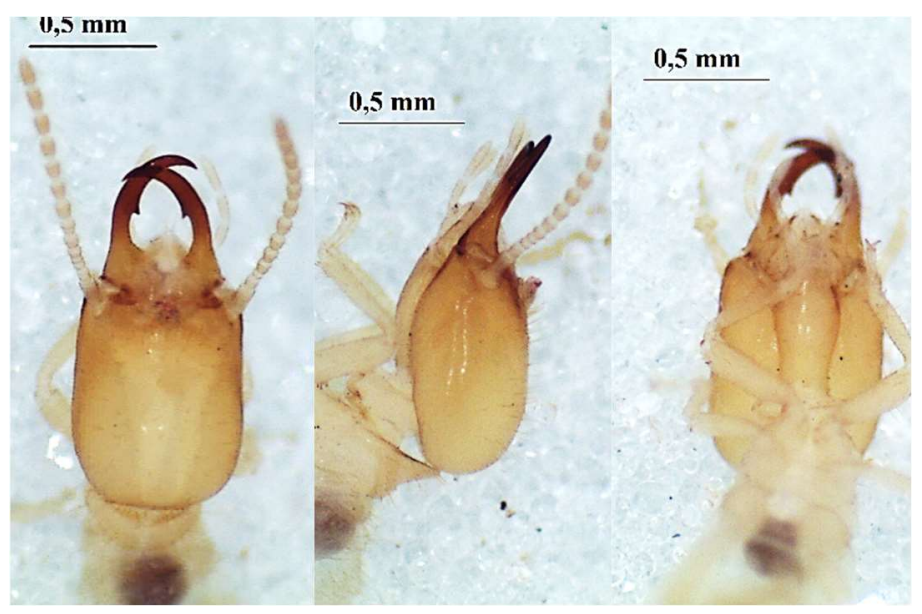

Figure 5. The head of Amitermes spinifer soldier in dorsal view (left), lateral view (middle) and ventral view (right).

\subsection{Amitermes truncatidens}

Table 4. The measurements (mm) of the soldiers of Amitermes truncatidens.

\begin{tabular}{ccc}
\hline & Range $(\mathbf{m m})$ & Mean \pm SD \\
\hline Head length & $1.01-1.13$ & $1.064 \pm 0.037$ \\
Head width & $0.943-0.992$ & $0.966 \pm 0.016$ \\
Left mandible length & $0.522-0.577$ & $0.547 \pm 0.023$ \\
Pronotum width & $0.564-0.576$ & $0.575 \pm 0.007$ \\
Gula width & $0.27-0.314$ & $0.284 \pm 0.021$ \\
Hind tibia length & $0.756-0.816$ & $0.785 \pm 0.025$ \\
\hline
\end{tabular}

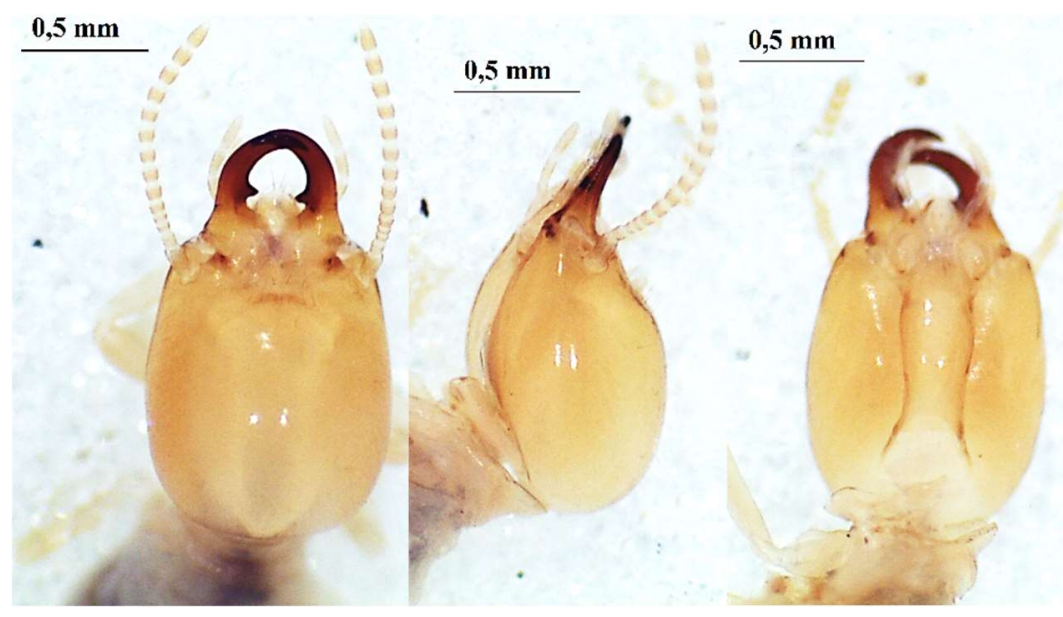

Figure 5. The head of Amitermes truncatidens soldier in dorsal view (left), lateral view (middle) and ventral view (right).

\subsection{Result of factorial discriminant analysis}

Although A. evuncifer and A. truncatidens measurements were close (Table 1 and 4) the factorial discrimant analysis showed that the are separate species (Figure 6), as well as the other two spcies (A. guineensis and A. spinifer). 


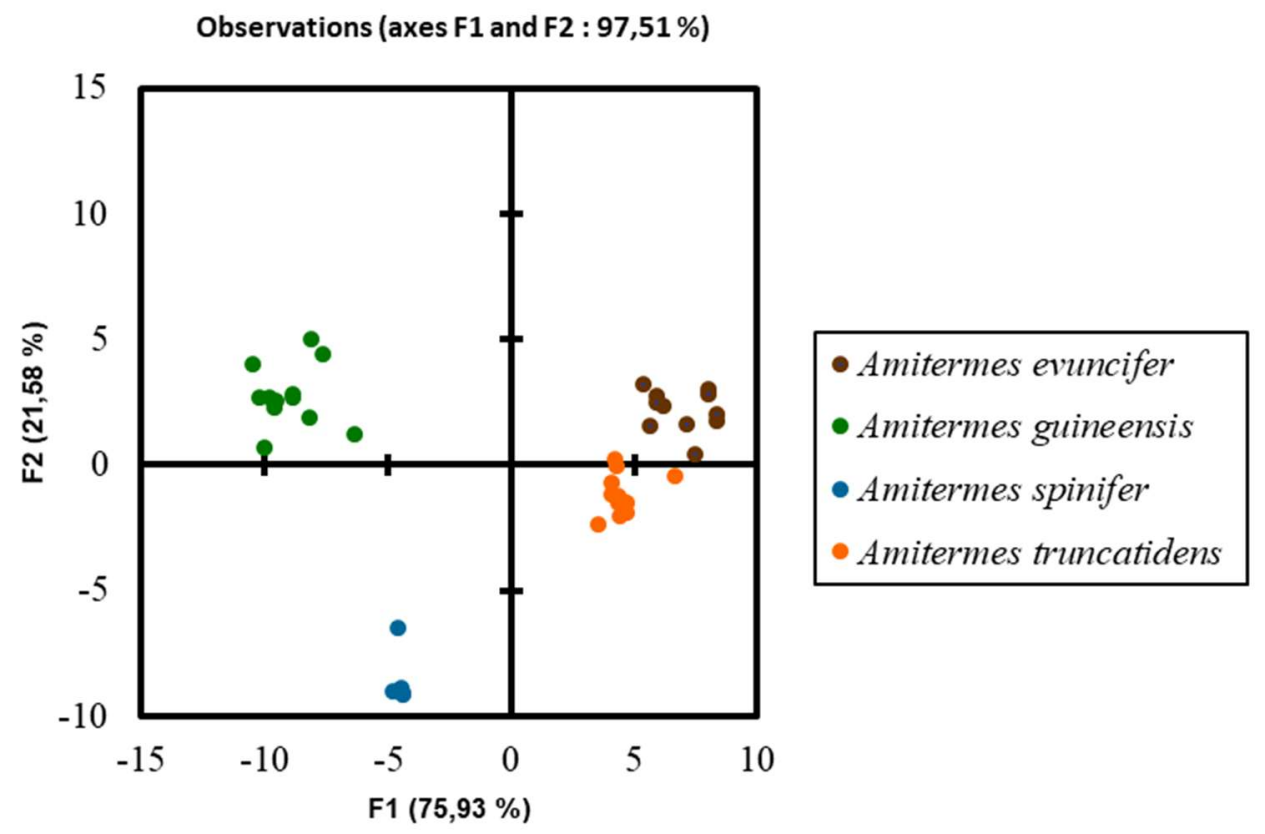

Figure 6. Separation of Amitermes species

\section{Discussion}

All the representative caste (Imago, soldiers and workers) of the four Amitermes species were already described [11]. In our study, the ranges and means of the measurements of soldiers fall within the ranges and means of respective species described by Sands [11]. Amitermes spinifer had the shorter and the smaller head of all while A. guineensis had the longer and the larger one.

\section{Conclusion}

Based on the measurements of parts of the heads and also the shape of mandible, we believe that there are at least four different species of Amitermes species in Togo. This study was the first in Togo to present Amitermes species with their respective measurements and pictures. It could be used as illustrated reference work for future taxonomic researches.

Author Contributions: Conceptualization, B.D.K., A.B.N. and A.I.G.; methodology, T.Q.E., B.D.K., A.B.N.and A.I.G.; software, B.D.K. and A.B.N.; validation, T.Q.E., B.D.K., A.B.N., B.B.S., and A.I.G.; formal analysis, T.Q.E., B.D.K., A.B.N.; investigation, T.Q.E., B.D.K., and B.B.S.; data curation, T.Q.E., B.D.K. and A.B.N.; writing - original draft preparation, B.D.K.; writing - review and editing, T.Q.E., B.D.K., A.B.N., B.B.S., and A.I.G.; visualization, T.Q.E., B.D.K., A.B.N., B.B.S., and A.I.G.; supervision, B.D.K., and A.B.N.; project administration, A.B.N. and A.I.G.; funding acquisition, A.B.N. All authors have read and agreed to the published version of the manuscript.

Funding: This study was part of a project financed by UEMOA (Union Economique et Monétaire Ouest Africaine).

Institutional Review Board Statement: Not applicable.

Informed Consent Statement: Not applicable.

Data Availability Statement: The data presented in this study are available on request from the corresponding author.

Acknowledgments: The authors are grateful to the authorities of the "Ministère de l'Environnement et des Ressources Forestières" for the logistics and other facilities. We thank villagers in sampling localities for their help in the field.

Conflicts of Interest: The authors declare no conflict of interest. 


\section{References}

1. Grassé, P.P. Recherches sur la biologie des termites champignonnistes (Macrotermitinae). Annales des Sciences Naturelles 1944, 6, 97-171.

2. Bouillon, A.; Mathot, G. Quel est ce termite africain? Zooleo 1965, 1, 1-115.

3. Josens, G. Etudes biologique et écologique des Termites (Isoptera) de la savane de Lamto-Pakobo (Côte d'Ivoire). Thèse de doctorat d'Etat, Université Libre de Bruxelles 1972.

4. Ruelle, J.E. Isoptera. In Biogeography and Ecology of Southern Africa; Werger, M.J.A. ; van Bruggen, A.C. Publishers: Springer Netherlands, 1978; pp. 748-762.

5. Silvestri, F. Termitidi raccolti da L. Fea alla Guinea Portoghese e alla Isole, S. Thomé, Annobon, Principe e Fernando Poo. Annali Museo Civico di Storia Naturale di Genova 1912, 45, 211-255.

6. Silvestri, F. Contribuzione alla conoscenza dei Termitidi e Termitophili dell'Africa occidentale. I. Termitidi. Bolletino del Laboratorio di Zoologia Generale e Agraria della R Scuola Superiore d'Agricoltura 1914, 9, 1-146.

7. Sjöstedt, Y. Revision der Termiten Afrikas. 3. Monographie. In Kungl Svenska Vetenska Akademiens Handlingar; Almqvist \& Wiksells Boktryckeri-A.-B.: Stockholm, Sweden, 1925; Volume 3, pp. 1-435.

8. Emerson, A.E. Termites of the Belgian Congo and the Cameroon. Bull. Am. Mus. Nat. Hist. 1928, 57, $212-222$.

9. Grassé, P.P. Recherches sur la systématique et la biologie des termites de l'Afrique occidentale française. Première partie: Protermitidae, Mesotermitidae et Metatermitidae (Termitinae). Annales de la Société Entomologique de France 1937, 106, 1-100.

10. Roy-Noël, J. Le parc national du Niokolo-Koba. VIII. Isoptera. Mémoire de l'IFAN 1969, 84, 113-178.

11. Sands, W.A. The Termites Genus Amitermes in Africa and the Middle. Nat. Resour. Inst. Bull. 1992, 51, 1-140.

12. Jones, D.T.; Eggleton, P. Sampling termite assemblages in tropical forests: Testing a rapid biodiversity assessment protocol. J. Appl. Ecol. 2000, 37, 191-203.

13. Dosso, K. ; Konaté, S. ; Aïdara, D. ; Linsenmair, K.E. Termite diversity and abundance across fire-induced habitat variability in a tropical moist savanna (Lamto, central Côte d'Ivoire). J. Trop. Ecol. 2010, 26 (3): 323-334.

14. Hausberger, B. ; Kimpel, D. ; van Neer, A. ; Korb, J. Uncovering cryptic species diversity of a community in a West African Savanna. Mol. Phylogenet. Evol. 2011, 61(3): 964-969.

15. Schyra, J. ; Korb, J. Termite Communities along A Disturbance Gradient in a West African Savanna. Insects 2019,10 (1): 1-17.

16. Effowe, TQ, Kasseney BD, Ndiaye AB, Sanbena BB, Amevoin K, Glitho IA. Termites' diversity in a protected park of the northern Sudanian savanna of Togo (West Africa). Nat. Conserv. 2021, 43: 79-91. 